\title{
Desvendar os Segredos das "Pedras Ferventes". EXPERIÊNCIAS COM ZEÓLITOS AO NÍvEL DO ENSINO SECUNDÁRIO
}

\author{
Nelson Nunes* e Angela Martins
}

\begin{abstract}
No o presente trabalho são descritas três experiências laboratoriais que visam dar a conhecer as propriedades dos zeólitos. As atividades, direcionadas para os alunos do Ensino Secundário, abordam a aplicabilidade dos zeólitos em três vertentes: (i) como materiais adsorventes, com aplicação em processos de descontaminação de efluentes gasosos e de águas; (ii) como permutadores iónicos, fazendo parte da formulação de detergentes com a função de amaciamento de águas e (iii) como catalisadores heterogéneos, usados maioritariamente em processos de refinação e petroquímica, bem como em algumas reações de química fina.
\end{abstract}

\section{INTRODUÇÃO}

O nome zeólito foi dado há cerca de 250 anos a uma família de minerais cristalinos (aluminossilicatos hidratados) e teve a sua origem quando o mineralogista sueco Crönsted descobriu que certos minerais (pedras), quando aquecidos, pareciam "ferver". O nome com que passaram a designar-se resulta da composição das palavras gregas zeo (ferver) e lithos (pedra).

Existe uma vasta bibliografia sobre zeólitos, maioritariamente publicada em língua inglesa. Existem também duas obras de referência editadas pela Fundação Calouste Gulbenkian e escritas em português: Catálise Heterogénea [1] e Zeólitos, um nanomundo ao serviço da catálise [2].

Ambas transmitem, de forma pedagógica e acessível, os conceitos básicos sobre zeólitos e suas propriedades, explorando as suas aplicações, com particular destaque para o seu papel como catalisadores. O autor comum nestas duas publicações é o recentemente falecido Professor Fernando Ramôa Ribeiro, pioneiro dos estudos sobre zeólitos em Portugal, cujo legado como professor, investigador ou orientador de numerosos alunos de mestrado e doutoramento, muito contribuiu para a divulgação das potencialidades destes materiais nas suas várias aplicações.

\footnotetext{
* Área Departamental de Engenharia Química, Instituto Superior de Engenharia de Lisboa (ISEL), Rua Conselheiro Emídio Navarro, 1, 1950-007 Lisboa E-mail: nnunes@deq.isel.ipl.pt
}

Os zeólitos podem ser divididos segundo a sua origem: naturais ou sintéticos. Os zeólitos naturais são normalmente encontrados em rochas vulcânicas ou metamórficas e o seu crescimento ocorre sob condições geológicas específicas (temperatura baixa e $\mathrm{pH}$ de 8-9). Inicialmente, estes materiais eram considerados apenas como curiosidades mineralógicas, mas, em 1925, foi descoberta no zeólito chabazite a propriedade de reter água e álcool etílico, mas não a acetona e o benzeno, surgindo daí a denominação "peneiros moleculares", atribuída por McBain em 1932.

Apenas a partir de 1945 os zeólitos naturais foram utilizados de forma sistemática na purificação de misturas de gases, mas cedo se mostraram insuficientes para satisfazer investigadores e industriais. Assim, em 1948, surgiram os primeiros zeólitos sintéticos. A Associação Internacional de Zeólitos (International Zeolite Association $I Z A)$, que classifica estes materiais, compilou o surpreendente número de
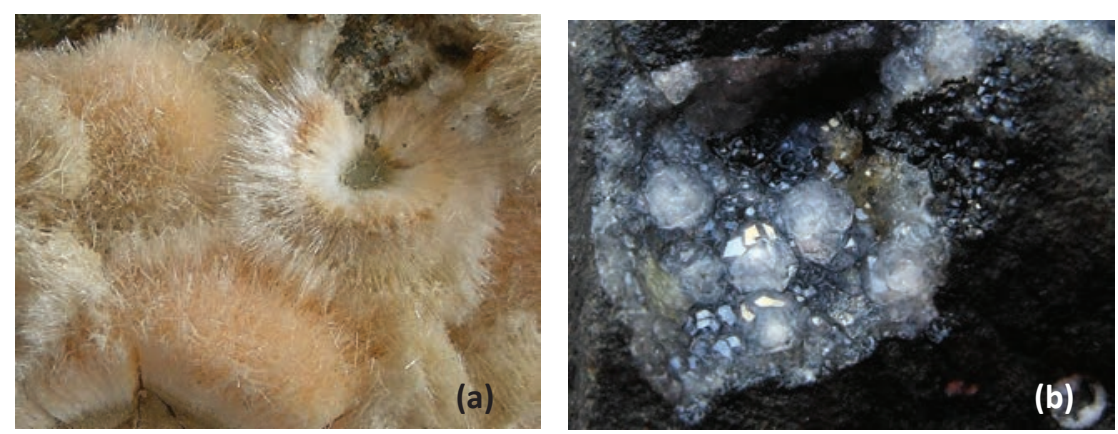

Figura 1 - Imagens de zeólitos naturais: Natrolite, $\mathrm{Na}_{2} \mathrm{Al}_{2} \mathrm{Si}_{3} \mathrm{O}_{10} \cdot 2 \mathrm{H}_{2} \mathrm{O}$, Lomba dos Pianos, Magoito, Sintra (a); Analcime, $\mathrm{Na}_{2} \mathrm{Al}_{2} \mathrm{Si}_{4} \mathrm{O}_{12} \cdot 2 \mathrm{H}_{2} \mathrm{O}$, Valejas, Oeiras (b); Imagens gentilmente cedidas por Rui P. Nunes [4]
201 estruturas sintéticas (outubro de 2011), enquanto na natureza só foram encontrados menos de 50 [3].

Em Portugal existem alguns locais onde é possível observar zeólitos naturais. O local mais privilegiado situa-se num afloramento que se insere no Complexo Vulcânico de Lisboa, situado entre as praias da Samarra e Magoito, conhecido como Lomba dos Pianos. Atinge uma espessura de cerca de 20 m e abrange uma área com cerca de $3 \mathrm{~km}$. O Maciço de Monchique, no Algarve, está também referenciado como um dos mais importantes da Europa [4-6]. A Figura 1 mostra algumas imagens de zeólitos naturais captadas em Portugal.

Alguns exemplares de zeólitos naturais portugueses e de outras origens podem também ser observados em alguns museus nacionais, como é o caso do Museu Alfredo Bensaúde ou do Museu de História Natural, onde também se encontra informação complementar. 
Do ponto de vista microscópico, os zeólitos apresentam-se sob a forma de pequenos cristais na ordem dos micra $\left(1 \times 10^{-6} \mathrm{~m}\right)$. A Figura 2 mostra imagens de microscopia eletrónica de varrimento (Scanning Electron Microscopy - SEM) de vários zeólitos com morfologias variadas, que vão desde cristais de forma cúbica (zeólito A), a placas alongadas (zeólito ZSM-5) ou a agregados em forma de folhas (zeólito MCM-22).

Quimicamente, os zeólitos são aluminossilicatos cristalinos constituídos por tetraedros de $\mathrm{SiO}_{4}$ e $\mathrm{AlO}_{4}$ ligados entre si por átomos de oxigénio. Acomposição dos zeólitos pode ser expressa pela fórmula estrutural empírica: $\left[\left(\mathrm{SiO}_{2}\right)\left(\mathrm{AlO}_{2}\right)_{\mathrm{x}}^{-}\right] \mathrm{M}_{\mathrm{x} / \mathrm{n}}{ }^{\mathrm{n}+} \cdot \mathrm{wH}_{2} \mathrm{O}$, onde $\mathrm{M}$ representa um catião de valência $n$, usualmente alcalino ou alcalino-terroso, que é necessário para compensar a carga negativa da unidade que contém Al que é -1 [2, 3]. Assim, por
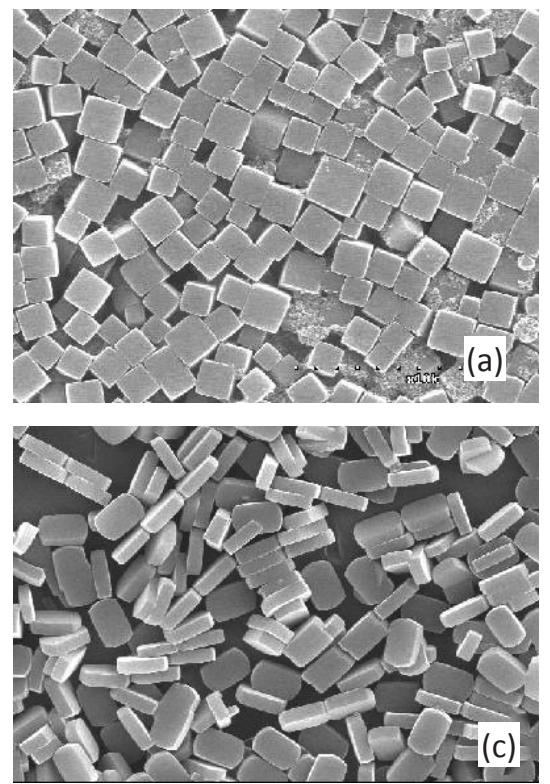

cada átomo de Al presente na estrutura, é necessário um catião de compensação a fim de preservar a sua eletroneutralidade, tal como se ilustra na Figura 3. Na natureza, a maioria dos zeólitos apresenta como catiões de compensação iões sódio $(\mathrm{Na})$, designando-se assim o zeólito (Z) correspondente como estando na forma sódica ou NaZ. Estes catiões podem ser trocados ou permutados por outros catiões, nomeadamente $\mathrm{NH}_{4}{ }^{+}$, ou $\mathrm{H}^{+}$, designando-se assim os zeólitos correspondentes por forma amónio, $\mathrm{NH}_{4} \mathrm{Z}$, ou forma protónica, $\mathrm{HZ}$.

A estrutura resultante, que pode ser mono, bi ou tridimensional, surge em função do arranjo particular que se estabelece entre as unidades estruturais, com formação de canais e cavidades de dimensão e forma variáveis, consoante o número de átomos de oxigénio que formam as aberturas dos canais [1, 2]. Cada arranjo estru-
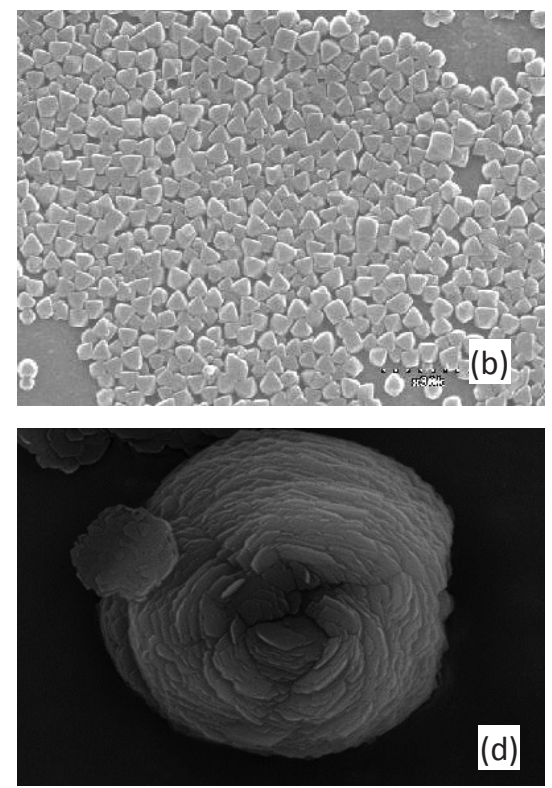

Figura 2 - Imagens de microscopia eletrónica (SEM) de zeólitos sintéticos: zeólito A (a); Y (b); ZSM-5 (c) [7]; MCM-22 (d); Dimensão dos cristais de 1 a $5 \mu \mathrm{m}$ tural é característico de um determinado tipo de zeólito e recebe uma denominação comercial e um código de três letras maiúsculas atribuído pela IZA [3]. Os zeólitos são ainda classificados de acordo com a dimensão das aberturas dos poros: zeólitos de poros pequenos, se possuírem anéis com 8 átomos de oxigénio, de que são exemplo os zeólitos A (Figura 4a) e chabazite, de poros médios, quando têm anéis com 10 átomos de oxigénio, encontrando-se entre outros o zeólito ZSM-5 (Figura 4b), e de poros largos, quando são constituídos por anéis de 12 átomos de oxigénio, onde se encontra o zeólito Y (Figura 4c) e a mordenite.

O processo de síntese de zeólitos é relativamente simples e emprega reagentes acessíveis. De forma muito simplificada, consiste em dissolver uma fonte de alumínio e outra de silício em meio alcalino. Atendendo à basicidade do meio, todos os recipientes em contacto com o meio reacional deverão ser de polietileno ou polipropileno. $\mathrm{Na}$ bibliografia encontram-se alguns protocolos de síntese bastante detalhados, entre os quais se recomenda a consulta da publicação de carácter mais pedagógica de Blatter e Schumacher [8], onde se expõe de forma detalhada a síntese do zeólito Y. Alerta-se no entanto que a síntese por si só não garante a obtenção de um material cristalino de boa qualidade. É essencial a caracterização do material obtido por algumas técnicas nem sempre disponíveis, como por exemplo a difração de raios- $X$, pelo método dos pós, a adsorção de gases e a espectroscopia de infravermelho. A maior aplicação dos zeólitos é na fabricação de detergentes (70\% em massa), onde são usados como amaciadores de águas, substituindo os fosfatos (tripolifosfato de sódio,

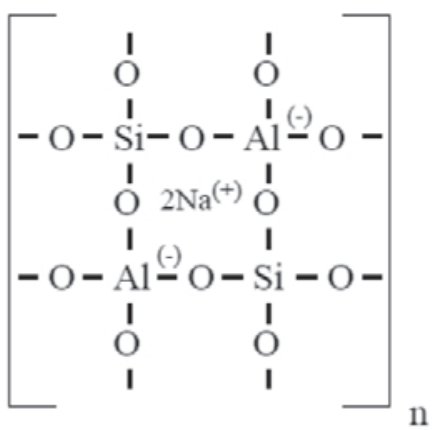

Figura 3 - Rede de tetraedros de um zeólito e respetivos catiões de compensação
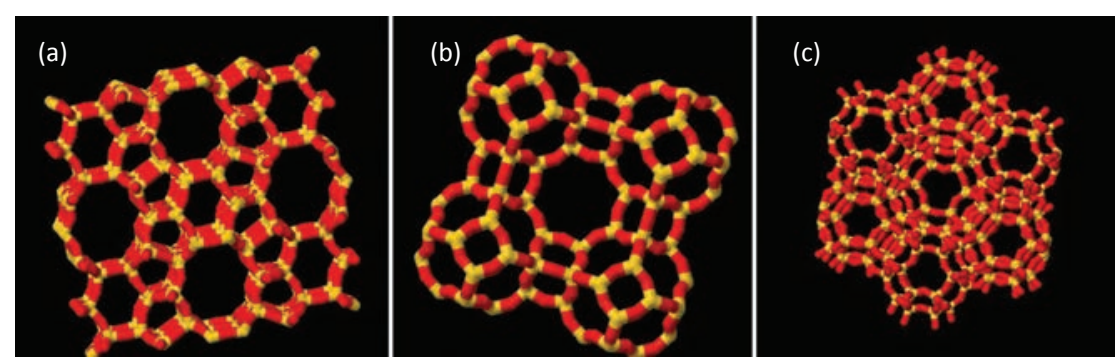

Figura 4 - Exemplos de estruturas de zeólitos: zeólito A (a); ZSM-5 (b) e Y (c) [3] 
$\left.\mathrm{Na}_{5} \mathrm{P}_{3} \mathrm{O}_{10}\right)$, que são compostos químicos nocivos para o meio ambiente, pois são responsáveis pela eutrofização de rios e lagos. Por outro lado, o facto dos zeólitos serem materiais microporosos, isto é, com canais e cavidades de diâmetro médio inferior a $2 \mathrm{~nm}$, faz com que estes materiais consigam reter no interior dos seus poros moléculas e iões de tamanho igual ou inferior ao das aberturas dos poros, excluindo as que são maiores. Esta propriedade é responsável pela vasta utilização dos zeólitos como adsorventes em processos de separação, por exemplo em purificação de gases ou de efluentes líquidos.

As aplicações mais importantes dos zeólitos em termos de valor acrescentado são no domínio da catálise. Os zeólitos são os componentes principais da maioria dos catalisadores usados na refinação de petróleo e petroquímica, desempenhando um papel cada vez mais importante na síntese orgânica e no tratamento de efluentes gasosos. Estas e outras aplicações dos zeólitos têm impulsionado a pesquisa destes materiais a um ponto nunca antes imaginado pelos pioneiros nesta área. Atualmente, no Ensino Secundário, a temática dos zeólitos é abordada no Programa de Química do $12 .^{\circ}$ Ano, na Unidade de Combustíveis, Energia e Ambiente, mas a sua aplicação fica restrita ao papel de catalisadores na indústria de refinação e petroquímica [9]. Com este trabalho propõe-se um conjunto de experiências que visam dar a conhecer as propriedades únicas destes materiais numa perspetiva mais abrangente. Assim, na vertente da adsorção pretende-se demonstrar a capacidade dos zeólitos na retenção de moléculas. Ao exemplificar a capacidade de amaciamento de uma água pretende-se ilustrar a propriedade de permuta iónica dos zeólitos. Finalmente, a síntese de um éster sob a ação de um

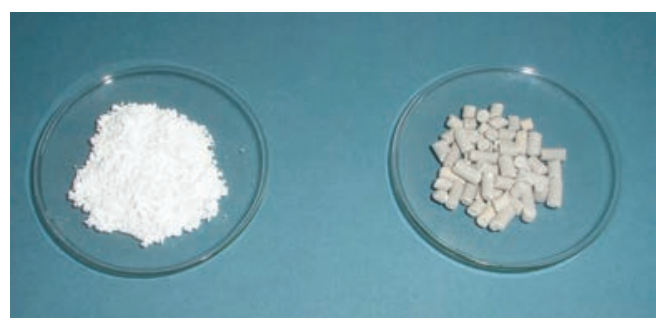

Figura 5 - Amostras do zeólito Y comercial nas formas de pó e extrudidos catalisador ácido permitirá estabelecer a comparação entre um catalisador homogéneo, o ácido sulfúrico, e heterogéneo, o zeólito, evidenciando as características mais económicas e amigas do ambiente deste último, ao permitir a fácil recuperação e regeneração do catalisador. Este trabalho foi desenvolvido no contexto do programa de Ocupação Científica de Jovens nas Férias, promovido pela Ciência Viva, baseado num conjunto de trabalhos desenvolvidos anteriormente no laboratório de Química Física do ISEL. O baixo custo dos reagentes, o diminuto número de equipamentos envolvidos e a facilidade de execução laboratorial torna-o adequado para implementar em laboratórios de escolas do Ensino Secundário.

\section{Materials usados no estudo}

Os zeólitos são materiais relativamente baratos que podem ser adquiridos a fornecedores de reagentes químicos. Também podem ser pedidos diretamente a alguns fabricantes industriais, que produzem estes materiais na ordem das toneladas para várias indústrias. Neste estudo foi usada uma amostra de zeólito A (Linde type A zeolite, Fluka, BCR705) e um zeólito Y na forma sódica (Aldrich, 33 441-3), em pó e extrudidos. Na Figura 5 apresentam-se amostras de zeólito $\mathrm{Y}$ em duas formas: pó e extrudidos.

\section{OS ZEÓLITOS COMO ADSORVENTES}

O termo adsorção descreve o fenómeno no qual existe um maior número de moléculas retidas na superfície de um sólido do que no meio (líquido ou gasoso) que o rodeia. A elevada capacidade de adsorção dos zeólitos foi reconhecida desde muito cedo, sendo aliás uma das suas primeiras utilizações conhecidas. Para demonstrar esta propriedade promoveu-se o contacto entre amostras de um zeólito $Y$ na forma sódica, NaY, e soluções de ácido acético de diferentes concentrações. Assim, através da utilização de uma simples técnica de titulação ácido/base é possível estimar a capacidade de adsorção do zeólito.

\section{Descrição da experiência}

Preparar de forma rigorosa soluções de ácido acético com um intervalo de concentrações compreendido entre 0,010 e 0,30 M, partindo de uma solução padrão $1 \mathrm{M}$ (recomenda-se um mínimo de 6 soluções). Pesar num vidro de relógio, usando preferencialmente uma balança analítica, amostras de cerca de $1 \mathrm{~g}$ de zeólito e transferir cada amostra para um erlenmeyer com tampa. Pipetar $100 \mathrm{~mL}$ de cada uma das soluções de $\mathrm{CH}_{3} \mathrm{COOH}$ para os erlenmeyers onde se encontram as amostras de zeólito devidamente identificadas. Tapar os erlenmeyers e colocá-los sob agitação durante aproximadamente 15 minutos, para que se estabeleça o equilíbrio entre o zeólito e o ácido acético. De cada filtrado fazer três tomas de $25 \mathrm{~mL}$, transferir para balões de titulação e titular com uma solução padrão 0,1 M de $\mathrm{NaOH}$, usando fenolftaleína como indicador. Registar o volume de titulante no ponto de viragem de incolor para carmim. Nesta experiência pode usar-se o zeólito sob a forma de pó ou extrudidos, sendo que no último caso as operações de pesagem e de recoIha de amostras para titulação é mais facilitada.

Na Figura 6 ilustra-se o material/equipamento usado nesta experiência.

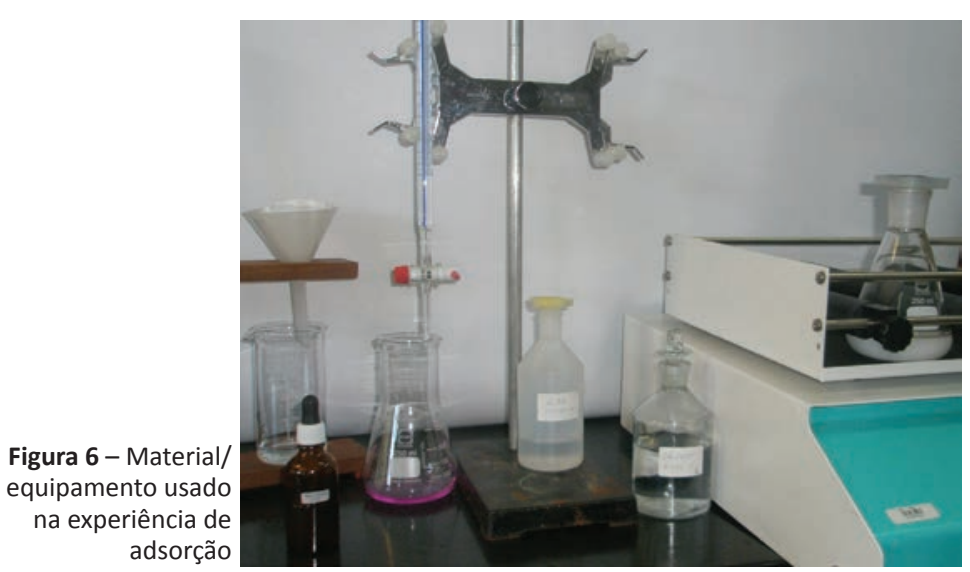


Para estimar a capacidade de adsorção do zeólito, considera-se a existência de um estado de equilíbrio entre as moléculas de $\mathrm{CH}_{3} \mathrm{COOH}$ em fase líquida $(A)$ e o zeólito $(Z)$ :

\section{$A(I)+Z$ (superfície) $\rightleftarrows A Z$ (superfície)}

O equilíbrio verifica-se quando a velocidade de adsorção (sentido direto) iguala a velocidade de desadsorção (sentido indireto). Pelos cálculos da titulação consegue determinar-se a concentração de equilíbrio de $\mathrm{CH}_{3} \mathrm{COOH}$. Este cálculo permite ainda determinar o número de moles de $\mathrm{CH}_{3} \mathrm{COOH}$ retidas no zeólito, por diferença entre o número de moles presentes inicialmente nas soluções e o número de moles presentes nos filtrados. $\mathrm{Na}$ Figura 7 mostra-se a representação gráfica da quantidade adsorvida, normalizada à massa de zeólito, em função da concentração de equilíbrio de ácido acético. A capacidade de adsorção do zeólito pode estimar-se pela quantidade máxima de $\mathrm{CH}_{3} \mathrm{COOH}$ adsorvida, isto é, pelo patamar da curva. A partir de um determinado valor de concentração de $\mathrm{CH}_{3} \mathrm{COOH}$, que varia consoante o tipo de zeólito usado, considera-se que toda a porosidade se encontra preenchida com moléculas de $\mathrm{CH}_{3} \mathrm{COOH}$.

Chama-se a atenção que a determinação da capacidade de adsorção de um zeólito por esta via constitui apenas uma estimativa que pretende ilustrar, com material corrente de laboratório, a propriedade de adsorção destes materiais. Considera-se desprezá-

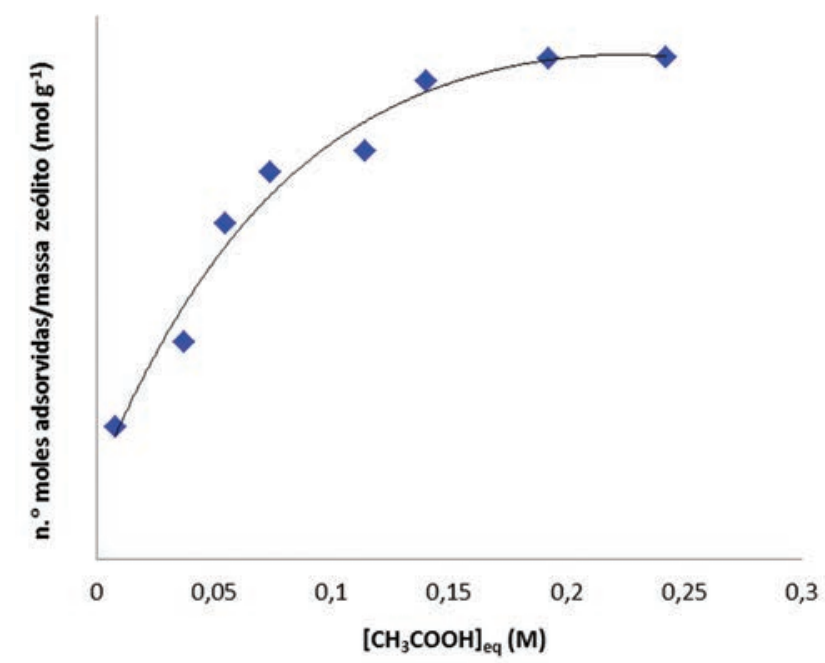

Figura 7 - Variação da quantidade adsorvida, normalizada à massa de zeólito, em função da concentração de $\mathrm{CH}_{3} \mathrm{COOH}$ de equilíbrio vel a reatividade do ácido acético com a superfície porosa do zeólito, desde que seja usado um zeólito na forma sódica [10]. Existem outras variantes de experiências de adsorção em fase líquida que podem ser consultadas na bibliografia mas requerem o uso de material e equipamento mais específico, como a adsorção de corantes acompanhada por espectroscopia na região espectral do visível com vista à remoção de corantes de efluentes provenientes de indústrias de tingimento [11].

\section{Os ZEÓLITOS COMO PERMUTADORES IÓNICOS}

A água da rede pública contém na sua composição quantidades variáveis de iões $\mathrm{Ca}^{2+}, \mathrm{Mg}^{2+}$ e $\mathrm{HCO}_{3}^{-}$. A concentração destes iões determina a "dureza da água", sendo o $\mathrm{Ca}^{2+}$ a espécie dominante. A presença destas espécies na água, aliada às temperaturas usadas vulgarmente nos programas de lavagem (superiores a $30^{\circ} \mathrm{C}$ ), leva à formação de depósitos sólidos sobre as resistências de aquecimento das máquinas de lavar, designados vulgarmente por calcário. Para colmatar este problema são adicionados aditivos aos detergentes, que têm por função remover estes iões por um processo chamado de "amaciamento".

Até à década de 70 eram usados fosfatos (tripolifosfato de sódio $\mathrm{Na}_{5} \mathrm{P}_{3} \mathrm{O}_{10}$ ), como aditivos, nos detergentes para amaciar a água de lavagem e permitir uma limpeza eficiente. No entanto, estes compostos químicos quando são despejados em lagos e rios facilitam a proliferação de algas, que por sua vez matam os peixes e outras formas de vida, por um processo designado por eutrofização.

Em 1974, a Henkel (empresa alemã de produtos químicos) introduziu o zeólito A nos detergentes em substituição dos fosfatos, usando esta inovação tecnológica para lançar uma imagem ecológica. Mais tarde, em 1978, a empresa americana Procter \& Gamble seguiu o exemplo e introduziu no mercado americano um novo produto que continha também zeólito A na sua composição substituindo, ainda que parcialmente, os fosfatos $[12,13]$.

Atualmente, várias marcas de detergentes sólidos e líquidos no mercado Europeu contêm cerca de 15-30\% em massa de zeólito. Apesar do zeólito A ainda predominar na maior parte dos detergentes, outras estruturas, como os zeólitos $\mathrm{P}$ e $\mathrm{X}$ têm vindo a ser utilizadas [12].

Como já foi referido anteriormente, os zeólitos possuem catiões de compensação a fim de garantirem a neutralidade da rede cristalina. Os catiões de compensação podem variar, no entanto, quer nos zeólitos naturais, quer nos sintéticos, os mesmos são geralmente as espécies $\mathrm{Na}^{+}$ou $\mathrm{K}^{+}$. Estes catiões podem ser trocados por outros que se encontram numa solução aquosa através de um processo designado por permuta iónica, que pode expressar-se de forma simplificada para catiões monovalentes pela equação seguinte [1]:

$$
A_{s}^{+}+B_{z}^{+}=A_{z}^{+}+B_{s}^{+}
$$

onde A é o catião a introduzir, designando-se por $A_{s}$ se está em solução ou por $A_{z}$ se está no zeólito e $B$ é o catião presente originalmente no sólido, designado por $\mathrm{B}_{\mathrm{z}}$ quando está em solução e por $\mathrm{B}_{\mathrm{s}}$ quando passa para a solução.

A propriedade de permuta iónica é responsável pela maior utilização dos zeólitos: a indústria de detergentes. Assim, quando o detergente contendo o zeólito entra em contacto com a água de lavagem, os iões $\mathrm{Na}^{+}$ou $\mathrm{K}^{+}$ que se encontram no zeólito são per- 
mutados pelos iões $\mathrm{Ca}^{2+}$ ou $\mathrm{Mg}^{2+}$ que se encontram na água de lavagem, Figura 8. Deste modo a concentração destes iões é reduzida, "amaciando" a água.

Sobre esta temática propõe-se uma experiência na qual se pretende avaliar a capacidade de amaciamento de um zeólito pela quantificação dos iões $\mathrm{Ca}^{2+}$ presentes numa água (considera-se que esta espécie se encontra em larga maioria) antes e após o contacto com uma amostra de um zeólito comercial. Também se pretende testar o comportamento de vários detergentes comerciais contendo zeólitos na sua composição [14].

\section{Descrição da experiência}

Parte I - Quantificação de $\mathrm{Ca}^{2+}$ numa água

A determinação da dureza da água efetua-se de modo simples por titulação complexiométrica dos iões $\mathrm{Ca}^{2+}$ com ácido etilenodiaminotetraacético (EDTA) na presença de um indicador [15]. A quantificação de $\mathrm{Ca}^{2+}$ pode ser feita numa amostra de água real. No entanto, para simplificar a experiência, sugere-se a preparação de uma solução 0,01 M de $\mathrm{CaCl}_{2}$ usando água desionizada. Este procedimento, que em nada interfere com a interpretação dos resultados, evita a interferência de outros iões normalmente presentes na água comum.

Pipetar $25 \mathrm{~mL}$ da amostra de água para um erlenmeyer. Adicionar $1 \mathrm{~mL}$ de solução aquosa de $\mathrm{NaOH} 2 \mathrm{M}$ (este procedimento é necessário, uma vez que as titulações com EDTA requerem meio básico). Adicionar uma pequena quantidade de indicador murexida. Titular com uma solução de EDTA 0,01 $\mathrm{M}$ até viragem de cor de vermelho para violeta.
Parte II - Quantificação de $\mathrm{Ca}^{2+}$ numa água após contacto com um zeólito puro

Nesta parte da experiência pretende-se dar a conhecer a capacidade de troca iónica do zeólito puro, neste caso permuta de $\mathrm{Na}^{+}$por $\mathrm{Ca}^{2+}$. Poderá usar-se qualquer zeólito, desde que os catiões de compensação sejam $\mathrm{Na}^{+}$(forma sódica) ou, menos comum, $\mathrm{K}^{+}$. Será no entanto mais interessante a utilização do zeólito A, pois é o mais usado na formulação de detergentes. Pesar rigorosamente 250 mg de zeólito e transferir para um erlenmeyer ou balão. Adicionar $100 \mathrm{~mL}$ de amostra de água e colocar sob agitação durante $15 \mathrm{~min}$. Filtrar a suspensão de modo a remover o zeólito. Medir três tomas do filtrado para erlenmeyers e titular seguindo o procedimento anterior.

Parte III - Quantificação de $\mathrm{Ca}^{2+}$ numa água após contacto com um detergente contendo zeólito

Nesta parte da experiência repete-se o procedimento anterior, mas usando detergentes em pó comerciais contendo zeólitos na sua formulação, a fim de testar a sua capacidade de amaciamento. Os estudantes deverão ser convidados a testar o detergente que é costume usarem em casa, permitindo estudar o comportamento dos detergentes de diversos fabricantes, uma vez que as quantidades de zeólito adicionadas variam entre 15 a $30 \%$ em massa, consoante o fabricante. Informação mais detalhada sobre cada produto pode ser consultada nos websites dos respetivos fabricantes, conforme preconizado pela regulamentação da União Europeia (CE n. ${ }^{\circ}$ 648/2004).

Numa primeira etapa, pesar $1 \mathrm{~g}$ de detergente em pó e transferir para um erlenmeyer ou balão. Adicionar $100 \mathrm{~mL}$ de amostra de água e colocar sob agi- tação durante 15 min. A suspensão irá apresentar-se turva, pelo que é recomendável deixar repousar durante cerca de $24 \mathrm{~h}$ para medir três tomas de $25 \mathrm{~mL}$ do líquido sobrenadante, seguindo o mesmo procedimento de titulação descrito anteriormente.

A partir do volume de EDTA consumido em cada titulação, e atendendo a que a estequiometria $\mathrm{M}^{2+}$ : EDTA é de $1: 1$, pode facilmente calcular-se a quantidade de cálcio presente em cada alíquota. A quantidade de cálcio removida calcula-se por diferença entre a concentração de iões $\mathrm{Ca}^{2+}$ presentes inicialmente na amostra de água (Parte I) e após contacto com o zeólito (Parte II) ou detergente contendo zeólito (Parte III). A percentagem de zeólito presente em cada amostra de detergente pode ser estimada partindo dos cálculos efetuados para o zeólito puro, no entanto esta estimativa deverá ser feita com alguma reserva, pois o tipo de zeólito usado como puro e o que está presente nos detergentes podem não ter as mesmas características e, consequentemente, a capacidade de permuta ser diferente.

As condições reacionais descritas nas Partes II e III podem ser modificadas de modo a obter um maior leque de resultados. Sugere-se por exemplo a alteração da temperatura, usando como referência as temperaturas de lavagem habituais, permitindo assim estudar a influência deste parâmetro na cinética da permuta iónica.

Na Figura 9 mostra-se material/equipamento usado na experiência de quantificação de $\mathrm{Ca}^{2+}$ em amostras de água.

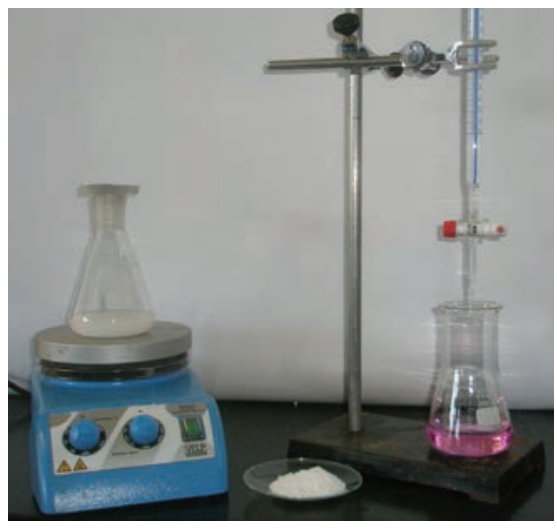

Figura 9 - Material/equipamento usado na quantificação de $\mathrm{Ca}^{2+}$ em amostras de água 


\section{OS ZEÓLITOS COMO CATALISADORES}

A catálise heterogénea é a aplicação tecnológica mais importante dos zeólitos. Estes materiais atuam como catalisadores em reações de refinação de petróleo, sendo a mais importante o cracking catalítico, que consiste na quebra de ligações carbono-carbono nos hidrocarbonetos de peso molecular elevado para originar fragmentos mais leves e ramificados, que são os constituintes principais das gasolinas. Também atuam como catalisadores em reações de petroquímica, com a transformação de moléculas aromáticas que servem de base a várias indústrias químicas, como por exemplo a indústria dos polímeros. Também na química fina, onde se engloba a produção de corantes alimentares ou produtos farmacêuticos e cosméticos, o papel dos zeólitos como catalisadores é cada vez mais relevante [2].
Nesta atividade experimental pretende-se ilustrar o papel de um zeólito como catalisador heterogéneo. Uma vez que a ocorrência da maior parte das reações que ocorrem na presença de zeólitos requerem a presença de centros ácidos de Brönsted, ilustrados na Figura 10, o zeólito a usar deverá estar na forma protónica - HZ, como por exemplo HY, que são zeólitos comerciais relativamente fáceis de encontrar.

No caso do zeólito disponível estar na forma sódica, poderá passar à forma amónio por permuta iónica com uma solução aquosa de $\mathrm{NH}_{4} \mathrm{NO}_{3} 2 \mathrm{M}$ durante $6 \mathrm{~h}$, sob refluxo, seguida de recuperação do pó por filtração, secagem em estufa e tratamento térmico a $300-400^{\circ} \mathrm{C}$ numa mufla a fim de remover $\mathrm{O} \mathrm{NH}_{3}$ e assim passar à forma protónica. Se a amostra estiver na forma $\mathrm{NH}_{4} \mathrm{Z}$ basta fazer o tratamento

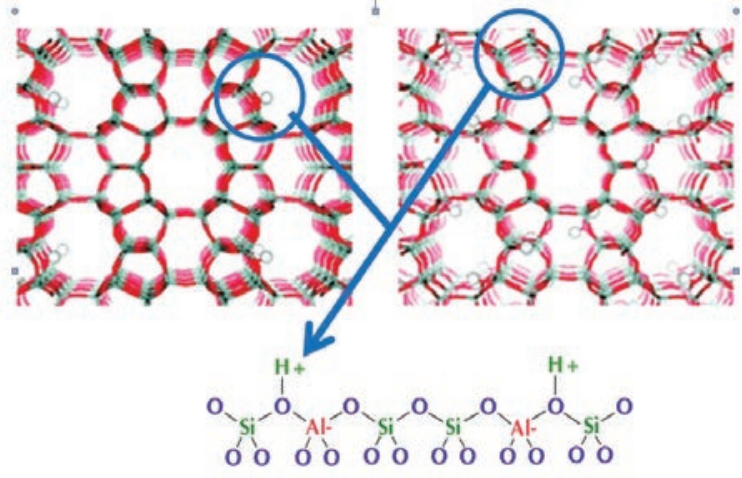

Figura 10 - Rede estrutural do zeólito, evidenciando os centros protónicos como catiões de compensação

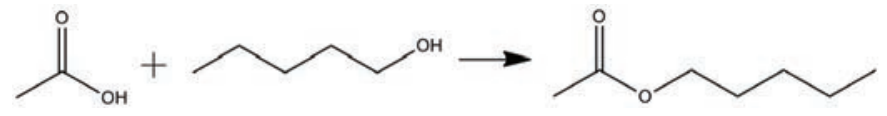

Figura 11 - Esquema reacional da reação de esterificação
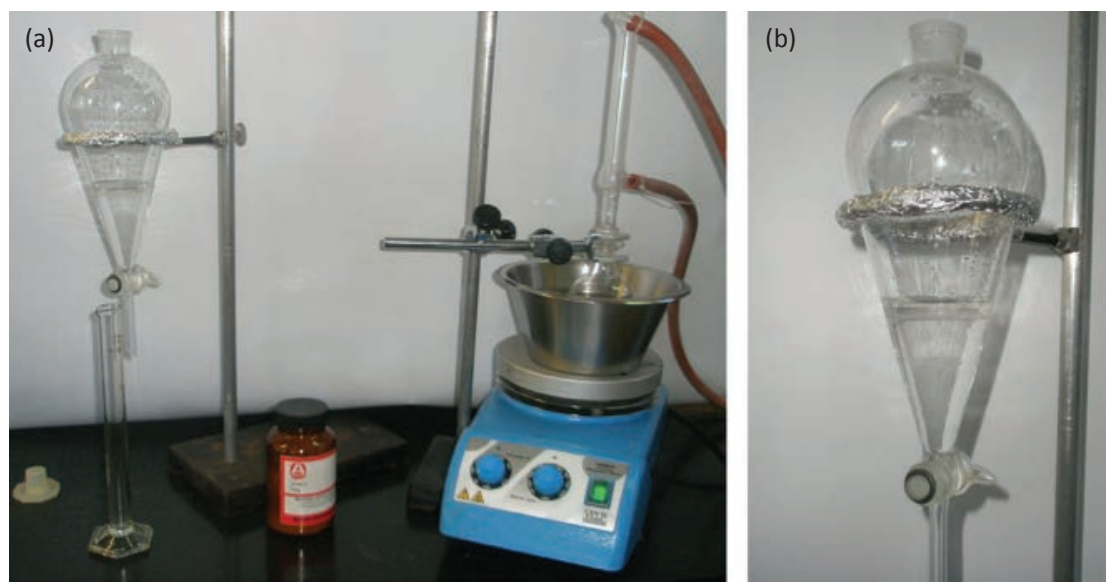

Figura 12 - Montagem de material/equipamento usada na experiência de catálise (a) Separação de fases na ampola de decantação (b)

térmico, se já se encontrar na forma protónica pode usar-se diretamente.

A reação que se pretende realizar envolve a formação de um éster a partir de um ácido carboxílico e um álcool (esterificação). Concretamente, pretende-se produzir etanoato pentílico (acetato de amilo), substância usada como aromatizante, a partir da reação entre ácido acético e 1-pentanol, na presença de um catalisador ácido, tal como se encontra esquematizado na Figura 11.

Para evidenciar as propriedades catalíticas do zeólito, a experiência poderá ser realizada em paralelo, usando um catalisador homogéneo clássico, o $\mathrm{H}_{2} \mathrm{SO}_{4}$, e um zeólito ácido [14].

\section{Descrição da experiência}

Num primeiro passo, introduzir $15 \mathrm{~mL}$ de ácido acético e $15 \mathrm{~mL}$ de 1-pentanol em dois balões de vidro com esmerilado (balão $A$ e balão $B$ ). No balão $A$, onde a reação irá ocorrer na presença de um catalisador heterogéneo, adicionar $2 \mathrm{~g}$ de zeólito HY. No balão $\mathrm{B}$, onde a reação irá acontecer em meio homogéneo, adicionar $0,5 \mathrm{~mL}$ de $\mathrm{H}_{2} \mathrm{SO}_{4}$ concentrado.

Em seguida, adaptar condensadores de refluxo a cada um dos balões e levar à ebulição durante $1 \mathrm{~h}$ usando uma placa ou manta de aquecimento. Após arrefecimento, filtrar a suspensão do balão $A$ (o zeólito que se recupera pode ser reativado por aquecimento a $450^{\circ} \mathrm{C}$ e usado novamente). Colocar as soluções provenientes dos balões A (filtrado) e B em copos contendo $150 \mathrm{~mL}$ de água gelada. Transferir para ampolas de decantação e observar a separação de fases. O ácido e o álcool não convertidos dissolvem-se na água enquanto o éster produzido é imiscível. Transferir para provetas o éster proveniente da reação catalítica homogénea e heterogénea e comparar os volumes obtidos pelas duas vias.

Na Figura 12a ilustra-se a montagem experimental usada na experiência. A separação de fases é visível na Figura $12 b$, onde a zona inferior corresponde à fase miscível em água e a zona superior à fase não miscível. 
Apesar do volume de éster obtido pela via heterogénea ser geralmente inferior ao obtido usando $\mathrm{H}_{2} \mathrm{SO}_{4}$ como catalisador homogéneo, deverá ser realçado que, enquanto o ácido é desperdiçado no final da reação, junto com a fase aquosa, o zeólito apresenta a vantagem de ser facilmente removido do meio reacional, podendo ser reciclado por aquecimento e novamente usado em posteriores ciclos reacionais. De notar que, usando diferentes álcoois e ácidos, a reação de esterificação pode ser também realizada obtendo evidentemente outros produtos finais. A escolha destes reagentes reflete unicamente a procura de uma etapa de separação entre regentes e produtos mais facilitada e, simultaneamente, a obtenção de um produto com características claramente distintas dos reagentes (neste caso o odor).

\section{CONCLUSÃO}

Com este conjunto de atividades espera-se fornecer aos alunos conhecimentos sobre zeólitos em três dos seus principais ramos de aplicação: adsorventes, permutadores iónicos e catalisadores heterogéneos. Do ponto de vista experimental, as atividades apresentadas são de simples execução, necessitando apenas de material básico de uso corrente de laboratórios escolares.

\section{Agradecimentos}

Os autores desejam agradecer:

- Prof. Celeste Serra, Presidente do Centro de Estudos de Engenharia
Química (CEEQ) do ISEL, pelo entusiasmo e incentivo à realização de Estágios de Ocupação de Férias da Ciência Viva no ISEL.

- André Sanches, EngeoWeb; Jorge Sequeira, Museu Geológico de Lisboa e Liliana Póvoas, Museu Nacional de História Natural, pelo interesse manifestado e cedência de informações sobre zeólitos naturais portugueses.

- Rui P. Nunes, pela cedência das fotografias de zeólitos naturais portugueses e informações dos melhores locais para os observar.

\section{REFERÊNCIAS}

[1] J.L. Figueiredo, F. Ramôa Ribeiro, "Catálise Heterogénea" 2. ${ }^{\mathrm{a}}$ Edição, Fundação Calouste Gulbenkian, Lisboa, 2007.

[2] M. Guisnet, F. Ramôa Ribeiro, "Zeólitos, um Nanomundo ao Serviço da Catálise", Fundação Calouste Gulbenkian, Lisboa, 2004.

[3] Ch. Baerlocher, L.B. McCusker, Database of Zeolite Structures: http://www. iza-structure.org/databases, consultado em janeiro de 2012.

[4] Rui P. Nunes' Mindat Home Page, http://www. mindat.org/user-2474. html, consultado em janeiro de 2012.

[5] F. Gonçalves, "Subsídios para o Conhecimento Geológico do Maciço Eruptivo de Monchique", Comunicações dos Serviços Geológicos de Portugal - Tomo LII, 16 pp, 1967.

[6] E.J. Gonzáles-Clavijo, V. Valadares, "O Maciço Alcalino de Monchique (SW português): Estrutura e Modelo de Instalação na Crosta Superior", Comunicações do Instituto Geológico e Mineiro, Tomo 90, pp. 43-64, 2003.

[7] http://hompi.sogang.ac.kr/zeolite/ egall2.htm, imagens SEM realizadas pelo Doutor Yun-Jo Lee, acedido em 27 de abril de 2012.

[8] F. Blatter, E. Schumacher, "The preparation of pure zeolite $\mathrm{NaY}$ and its conversion to high-silica faujasite", Journal of Chemical Education, 67 (1990) 519-521.

[9] http://www.educacao.te.pt, consultado em setembro de 2011.

[10] E. Kukulska-Zając, K. Góra-Marek, J. Datka, "IR and TPD studies of the reaction of acetic acid in zeolites NaHY", Microporous and Mesoporous Materials, 96 (2006) 216-221.

[11] S. Wang, H. Li, L. Xu, "Application of zeolite MCM-22 for basic dye removal from wastewater", Journal of Colloid and Interface Science, 295 (2006) 71-78.

[12] Zeolites for Detergents, as nature intended, Association of Detergent Zeolite Producers, CEFIC, January 2000.

[13] Zeolite A, Technical repport, Henkel $\mathrm{KGaA}$, with the assistance of HERA Environmental Task Force and HERA Huamn Health Task Force, January 2004.

[14] E.N.Coker, P.J. Davis, A. Kerkstra, H. van Bekkum, "Experiments with zeolites at the secondary-school level: Experience from the Netherlands", Journal of Chemical Education, 76 (1999) 1417-1419.

[15] Água, Determinação do teor em cálcio, Norma NP-506, 1967.

\section{Atualidade Científica}

\section{CaPtuRAndo O POTENCIAL dO DIÓXIDO DE CARBONO!}

O dióxido de carbono é um problema. Como gás do efeito de estufa, contribui para o aquecimento global e as suas concentrações crescentes na atmosfera são citadas como a causa de alterações climáticas antropomórficas. Mas agora, uma equipa de investigadores da Universidade de Bath avançou com a ideia de usar o dióxido de carbono como matéria prima potencial para produção de combustiveis. Davide Mattia, que lidera a equipa de investigação, inspirou-se no processo de Fischer-Tropsh, que usa um catalisador de ferro para catalisar a reação entre hidrogénio e monóxido de carbono e produzir uma mistura de alcanos que pode ser usada como combustível. O catalisador de Mattia, que funciona com monóxido de carbono e com dióxido de carbono, é também baseado em ferro, tomando a forma de nanopartículas de ferro suportadas em nanotubos de carbono.

Mattia descobriu que quando o dióxido de carbono e o hidrogénio são alimentados ao processo, o hidrogénio adsorve preferencialmente nos nanotubos de carbono e o dióxido de carbono contacta com as nanopartículas de ferro, reagindo com o hidrogénio que apresenta uma elevada concentração na vizinhança, aumentando assim a eficiência na formação de hidrocarbonetos. Pensando no futuro, Mattia e a sua equipa planeiam agora tentar usar o calor que é libertado nos gases de escape de centrais de energia elétrica para alimentar o processo, de modo a tornar neutro o seu ciclo de carbono. 
